\title{
Short-term foreign trips correlates of the four factors model of cultural intelligence
}

\author{
Bhawana Bhardwaj \\ School of Commerce and Management Studies, \\ Central University of Himachal Pradesh, Dharamshala, India \\ Dht Studies,
}

\begin{abstract}
Purpose - In today's global business environment, international assignments have become integral part of employee's job profile. Adaptation to a different cultural environment plays a role in affecting employee's performance. In such a situation, cultural intelligence plays an important role. In order to sustain in a diverse work setting, a global organization entails managers who are sensitive to different cultural requirements. Factors affecting cultural intelligence have been a major area of study. However, studies relating short-term foreign trips and their role on four aspect of cultural intelligence are lacking. Therefore, present study was undertaken to know role of foreign visits in affecting cultural intelligence among professionals of diverse background.
\end{abstract}

Design/methodology/approach - The present study is a primary study conducted for a sample of 120 respondents divided into two groups. One group comprised professionals having experience of foreign visits while other group comprised professionals who had not visited a foreign country. We use Levene's Test for equality of variances was applied to assess the difference of variation of cultural intelligence between two different groups of respondents.

Findings - The results revealed that short-term trips play a significant role in affecting metacognitive, cognitive and motivational components of cultural intelligence. However, behavior cultural intelligence is not affected by short-term trips significantly.

Research limitations/implications - Outcome of present research forms basis for future studies that can be conducted linking long-term trips and culture intelligence. This study is practically useful for improving cultural intelligence of professionals to enhance their success and effectiveness in international assignments. Originality/value - The study adds novelty to the field of cultural intelligence as prior studies were lacking in relating role of short-term trips on four different components of cultural intelligence.

Keywords Cultural intelligence, Foreign trips, International business, Culture

Paper type Research paper

\section{Introduction}

Expansion of a business internationally is significant in the era of globalization. Globalization has rendered the organizations a complex business environment where employees are exposed to unfamiliar and different cultural contexts. These cultural differences and intercultural elements increase the complication of international business (Zhang, 2013; Lin et al., 2012) and can lead to conflicts (Gabel et al., 2005). In order to mitigate the complications of diverse culture in a business, an effective communication is a vital requirement. Within a culture, communication process is facilitated by shared values. However, different cultures have different value sets which make the communication exigent. In such context, cultural intelligence has attracted the attention of researchers especially in business at global level.

(C) Bhawana Bhardwaj. Published in Rajagiri Management Journal. Published by Emerald Publishing Limited. This article is published under the Creative Commons Attribution (CC BY 4.0) licence. Anyone may reproduce, distribute, translate and create derivative works of this article (for both commercial and non-commercial purposes), subject to full attribution to the original publication and authors. The full terms of this licence may be seen at http://creativecommons.org/licences/by/4.0/legalcode

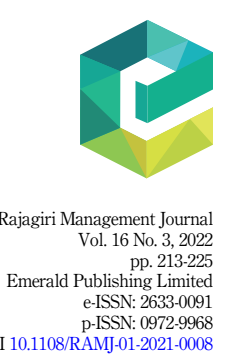

Received 20 January 2021 Revised 29 April 2021 Accepted 12 May 2021 
RAMJ 16,3
International organizations face cultural diversity which instinctively has both positive and negative impacts. However, the impact of diverse workforce varies depending upon the kind of differences that constitute the "diversity" in question (Milliken and Martins, 1996; Ely and Thomas, 2001). Contemporary organizations encourage cross-cultural management as a tool for organizational effectiveness. An employee high on cultural intelligence can play a significant role in bridging divides, knowledge and cultural gap. They can support an organization by educating peer groups about different cultures, transferring knowledge and facilitating interpersonal processes. In order to sustain in a diverse work setting a global organization entails managers who are sensitive to different cultural requirements. Cultural intelligence (CQ) can act as a tool to manage cultural diversity (Moon, 1999; Lee and Sukoco, 2010) individual and team creativity (Ali et al., 2019). Cultural intelligence also smoothen the progress of expatriate performance and success. Current situation in business houses urges importance of cultural intelligence (CQ) which can further facilitate effective adaptation to new cultural environment and knowledge transfer (Vlajčić et al., 2019).

Cultural intelligence (CQ) is capability of a person to perform better and successfully in an unfamiliar culture by acquiring and using cultural knowledge (Earley and Ang, 2003). It includes interpreting nonverbal cues in a similar way that individual's fellow citizen would infer (Earley and Mosakowski, 2004). Various studies on cultural intelligence elaborates that adjustment of an individual into a new culture is affected by his/her CQ level (Ang et al., 2006). Cultural intelligence also enhances decision-making power, individual well-being and job performance (Ang et al., 2007), ease out stress, emotional burnout and fatigue (Tay et al., 2008). Cultural intelligence (CQ) can play a major role in the job performance of individual as well as cross-cultural teams. The ability to strategize, persist and perform contributes to the stamina necessary to complete international assignments. Culturally intelligent employee has creativity as well as innovation, persistence and ability to strategize which in turn builds up stamina to complete international assignments. These findings suggest that cultural intelligence plays a significant role in international assignments through employee's adjustment and performance.

It has been said that "when in Rome, do as the Romans do": this means while in foreign land, follow the norms, rituals or customs of people who live there. Cultural intelligence can help an expatriate adapt in different culture. A new employee in a foreign land spends few or sometimes many weeks decoding the cultural code of country and the organization he has to work in. Cultural intelligence can play a significant role in the job performance of crosscultural teams. Intelligence has always been explored as a factor and indicator of managerial competence and leadership effectiveness but $\mathrm{CQ}$ is a relatively new theoretical concept and considered an important part of talent management in cross cultural contexts. Past research has identified evidence of failure of international business due to lack of effective human resource management (Dowling, 2008) and importance of expatriates' development to facilitate their cross-cultural adjustments (Zhang, 2013). Cultural intelligence facilitates expatriates' performance in international assignments and cross-cultural contexts (Lee and Sukoco, 2010). Cultural intelligence is also referred to as integral part of training programs in international business environment (MacNab et al., 2012) as it can lead to cultural adjustment (Lin et al., 2012). Therefore, cultural intelligence and factors affecting cultural intelligence have been a critical area of research for various researchers.

Various research studies have been conducted to investigate the factors affecting cultural intelligence. Organizations conduct simulation exercises to develop cultural intelligence. The simulation leads to increased capability on cross-cultural interaction and cross-cultural behavior. Few organizations use preliminary visits to facilitate cultural adjustment of expatriate and spend a considerable amount on it. Organizations rely on short-term assignments and preliminary visits for shorter terms from a month to a year (Mayerhofer et al., 2007). Only few studies have tried to understand role of international exposure on 
cultural intelligence (Engle and Crowne, 2014). Studies have also focused on role of study trips in enhancing cultural intelligence (Opengart, 2018). However, there is a dearth of studies confined to understand the impact of short-term foreign trips on four major components of cultural intelligence is lacking. Therefore, the present study has been undertaken to understand how four different facets of cultural intelligence namely metacognitive, affective and behavioral cultural intelligence are affected by short-term international assignments.

This research is based on primary study where CQ of employees working in various organizations who have visited foreign country for professional reasons have been compared with those whose have not taken up any foreign assignments. Thereafter, the difference in cultural intelligence of both the group is analyzed. It is argued that much can be gained in research and practice by knowing these factors and their relationships. The study can be practically helpful to the organization that uses preliminary visits and foreign assignment as a tool to facilitate cultural adjustment.

\section{Theoretical background}

According to Hofstede (1980) culture is "the collective programming of the mind which distinguishes the members of one human group from another." Culture has been identified as one of the most important variables influencing employee's behavior at work. The knowledge about culture can be used to interpret and generate social behavior (Spradley and McCurdy, 2012). It can be compared to an ocean with no boundaries containing water of both separate and shared sources (Fang, 2005). Intelligence quotient is considered as an indicator of managerial competence and effectiveness. However, cultural intelligence (CQ) is a newer concept that has hit the mainstream world. It is the ability of a person to perform better and efficiently in a culturally diverse environment. According to Earley and Ang (2003), it is "a multidimensional construct that encompasses an individual's capability to function and manage effectively in culturally diverse settings.” Four major parts of cultural intelligence are metacognitive CQ, cognitive CQ, motivational CQ and behavioral CQ (Earley and Ang, 2003). When a person attempts to understand and achieve cultural knowledge, he uses metacognitive component. When an individual has knowledge and awareness about cultures and its similarity and dissimilarity with own culture, it is referred to as cognitive CQ (Ang et al., 2007). Effort, enthusiasm and energy that an individual exerts for learning about cross-cultural situations is called motivational CQ. Behavioral CQ explains capability to use appropriate verbal and nonverbal actions in unfamiliar cultural situations.

\section{Literature review and research gap}

\section{Metacognitive cultural intelligence and foreign visits}

Global assignments have always been considered as a tool for developing cross cultural skills (Davies and Easterby-Smith, 1984). It has been observed that international exposure and foreign visits gives multiple hints and learnings by observing others and their behavior. Cultural interactions, thus, influence one's knowledge, awareness and perception of a culture (Crowne, 2008). Foreign visits lead to increased awareness and sensitivity for others' culture. Foreign visits to complete study programs leads to understanding and experiencing different culture leading to development of cultural competence (Carter et al., 2019). Due to international visits individuals become acquainted with the beliefs, rituals and norms of a culture (Engle and Crowne, 2014). It helps a person to gain knowledge, skills and behaviors required for surviving and performing in various cultural situations (Ting-Toomey and Kurogi, 1998).

International exposure gives learning and understanding through observing others behavior and reactions (Earley and Peterson, 2004). Thus, these exposures and interactions impact individual's learning and thoughtfulness of different cultures (Engle and Crowne,
Short-term foreign trips and cultural intelligence 
RAMJ

16,3

2014). Hence, providing a platform to employees to interact with people of different culture improve people's knowledge and indulgent for a new culture (Crowne 2013; Johnson et al., 2006). Therefore, it can be proposed:

\section{H1. Foreign visits will increase metacognitive cultural intelligence}

Foreign trips and cognitive cultural intelligence

Knowledge and awareness of values, norms, practices and rules and culture of a place is called cognitive culture intelligence (Ng and Earley, 2006; Ang et al., 2006). These also include ability to recognize cultural relationship, resemblance and uniqueness (Ang et al., 2020). Lustig and Koester (2006) argued that foreign travel increases the sensitivity of a person about cultural differences. Mostly with this understanding and learning, knowledge is imbibed through education as well as personal exposures and experiences (Ang et al., 2020). Some researchers are of opinion that cognitive CQ has two components namely culture general knowledge and cultural-specific knowledge (Van Dyne et al., 2012). A short-term visit can enhance intercultural wisdom and maturity (Opengart, 2018; King and Baxter Magolda, 2005). Thus, it can be proposed that:

H2. Foreign visits will increase cognitive cultural intelligence

\section{Foreign trips and motivational cultural intelligence}

Motivational CQ is the motivation of a person to become familiarized and accustomed to the new cultural environment Blasco et al. (2012), Lin et al. (2012). This also includes learning as well as functioning in different cultural situations (Ang et al., 2020, 2006, 2007). It involves adaptation and goal to interaction and adjustment to an unfamiliar culture and goal setting (Earley and Ang, 2003; Ng and Earley, 2006; Earley and Peterson, 2004; MacNab et al., 2012). It is the foundation of enthusiasm to adjust and adapt to a totally different cultural environment (Ang et al., 2020). This also acts a facilitator of expatriate's adaptability and performance (Wu and Ang, 2011). It has been observed that individual motivational CQ plays a role in overcoming frustration and anxiety arising from interaction in a diverse culture (Lin et al., 2012). Hence, we propose that:

H3. Foreign visits will increase motivational cultural intelligence

\section{Foreign trips and behavioral cultural intelligence}

Behavioral CQ presents the action part of cultural intelligence construct (MacNab et al., 2012; Ang et al., 2020; Earley et al., 2006). Using appropriate verbal and nonverbal behaviors such as postures, tones, gestures and body language is part of behavioral CQ (Engle and Crowne, 2014; Lin et al., 2012; Ang et al., 2007; Ng and Earley, 2006). An individual can imbibe appropriate behavior either by observation or by experience (Phillion, 2002). International visits provide a platform to observe or examine another national culture. It also helps a person in adopting and modifying behavior according to cultural expectation (Johnson et al. 2006). Thus, it is believed that intercultural interaction results in psychological impacts on one's behaviors (Sam and Berry, 2010). Thus, we can propose that:

\section{H4. Foreign visits will increase behavioral cultural intelligence}

Visiting foreign countries expose an expatriate to diverse and different culture. This study was taken up to study the impact of global business tours taken up by professionals as part of their job on cultural intelligence. The major objective of the research is to find out how exposure due to short-term trip of 3-7 days can impact various components of cultural intelligence of an individual. The study has been undertaken with following objectives: 
(1) To find out role of short-term foreign trips in influencing metacognitive cultural intelligence.

(2) To understand the role of short-term foreign trips in influencing cognitive cultural intelligence.

(3) To find out role of short-term foreign trips in influencing motivational cultural intelligence.

(4) To assess role of short-term foreign trips on behavioral dimensions of cultural intelligence.

\section{Methodology}

Cultural intelligence of the respondent was assessed through a questionnaire based on Cultural Intelligence Scale (CQS) (Ang et al., 2007). The instrument has undergone widespread validation process. A structured questionnaire based on the same instrument has been used for meeting current study's objectives. The questionnaire consisted two sections: first section included statements related to demographic variables, foreign visits, frequency and duration of foreign visits of the respondents.

Second section consisted statements relating to four different components of cultural intelligence. The scale consisted four statements relating to metacognitive CQ, and six statements for cognitive CQ, five statements relating to motivational CQ and five statements corresponding to behavioral CQ. Response of the subjects was sorted on a seven-point scale varying from strongly disagree (1) to strongly agree (7). Thus, the questionnaire consisted a total of 20 statements relating to four different components of cultural intelligence.

To understand the role of short-term study abroad, a total sample of 120 respondents were taken from various organization such as banking, education and telecom and were divided into two groups. The respondents were selected through convenient sampling. First group comprised 60 respondents who had not visited any foreign country and second group also included 60 respondents who had visited foreign counties due to their job requirement. We used Levene's test for equality of variances to assess the difference of variation of cultural intelligence between these two different groups of respondents (see Table 1).

\section{Results}

Table 2 clearly indicates that the mean score for cultural intelligence components is different for both the groups. The score of cultural intelligence components is more in case of the

\begin{tabular}{|c|c|c|c|c|c|}
\hline Cronbach's alpha & \multicolumn{3}{|c|}{ Cronbach's alpha based on standardized items } & No. of items & \multirow{2}{*}{$\begin{array}{r}\text { Table } 1 . \\
\text { Reliability of responses }\end{array}$} \\
\hline 0.650 & & 0.765 & & 20 & \\
\hline Foreign visit & Mean MC & Mean COG & Mean MOT & Mean BEH & \\
\hline \multirow{2}{*}{$\begin{array}{l}\text { (Group 1) } \\
\text { Visited foreign country } \\
\text { (Group 2) } \\
\text { Not visited any country }\end{array}$} & 4.1618 & 3.5 & 3.4290 & 3.7020 & \\
\hline & 3.98 & 3.111 & 3.1490 & 3.5420 & $\begin{array}{r}\text { Table } 2 . \\
\text { Mean score of cultural } \\
\text { intelligence }\end{array}$ \\
\hline
\end{tabular}


RAMJ

16,3

respondents who have visited foreign countries. Thus, those who have visited foreign countries have shown a better score for cultural intelligence as compared to those respondents who have not visited any foreign country. Thus, it can be drawn that short-term foreign trips play a role in influencing the cultural intelligence of an individual.

As Table 3 shows, $p<0.05(0.023)$ the variances in the two groups is significantly different. Therefore, bottom row was considered for interpreting the results. It is evident that sig (2-tailed) value is less than 0.05 which shows that metacognitive cultural intelligence is a statistically significant different in both the groups. Thus, it can be interpreted the short-term foreign visits play a role in influencing metacognitive cultural intelligence of the respondents. Thus, people having exposure to different culture tend to understand difference in culture better than those employee who have never visited any foreign country.

Table 4 depicts role of foreign visits in cognitive cultural intelligence. As the $p<0.05$ $(0.043)$ it can be inferred that the variance of cognitive cultural intelligence is significantly different in both the groups of population. Further, it can be interpreted from the bottom row of the table significant (2-tailed) value is $<0.05(0.047)$ which infers that the cognitive cultural intelligence varies significantly between two groups. Thus, the individuals having exposure to foreign countries are better in understanding the relation and difference between their culture and foreign culture better than the individual who have not visited any country.

Table 5 shows the role of foreign visits in affecting motivational cultural intelligence. As it is evident from the table that value $p<0.05(0.000)$ which indicates that the motivation cultural intelligence vary significantly in both the groups. The sig (2-tailed) value is 0.015 which indicates that there is significant role of foreign visits in influencing motivational cultural intelligence. Hence, the individuals having exposure to foreign counties are more motivated to learn about new culture.

Table 6 shows the role of foreign visits in behavioral cultural intelligence. As it is evident from the table value $p<0.05$ (i.e. 003) which indicates that the behavioral cultural intelligence vary significantly in both the groups. However, this variation is not significant as sig (2-tailed) value is 0.088 . This indicates that foreign visits do not play a significant role in influencing behavior cultural intelligence (see Table 7).

\section{Conclusion, managerial implication and future scope}

Cultural intelligence has been a topic of interest for researchers as well for organizations due to increased diversity at workplace as well as globalization of business. Prior studies have either focused role of international trips or long-term professional assignment on CQ. A study on role of short-term professional trips specifically identifying their role on four different components of cultural intelligence is lacking. Therefore, the present study was undertaken to know the role of short-term foreign trips on four different components of cultural intelligence among the professionals of different background. The study revealed that overall cultural intelligence score of the employees who have visited foreign country is higher than those who have not visited any foreign country. This clearly indicates that giving short-term assignments of foreign trips to employees improved their cultural intelligence. The business visits can provide prospects to identify various challenges in cross-cultural environment including language, culture, human resource and governmental policies and relations. There is variability in the cultural intelligence of employees in two conditions, i.e. whether they visit for a foreign assignment or not. Present study revealed that components of cultural intelligence namely metacognitive $C Q$, cognitive $C Q$, motivational $C Q$ vary significantly with foreign visits while there is no significant difference in case of behavior CQ. Therefore, it can be suggested that the companies having international expansion of business should take cognizance of the role of foreign trips as a tool for enhancing cultural intelligence which can further enhance cultural adaptability. The present study focused on the role of short-term 
RAMJ

16,3

220

Table 4.

Cognitive cultural

intelligence and foreign visits

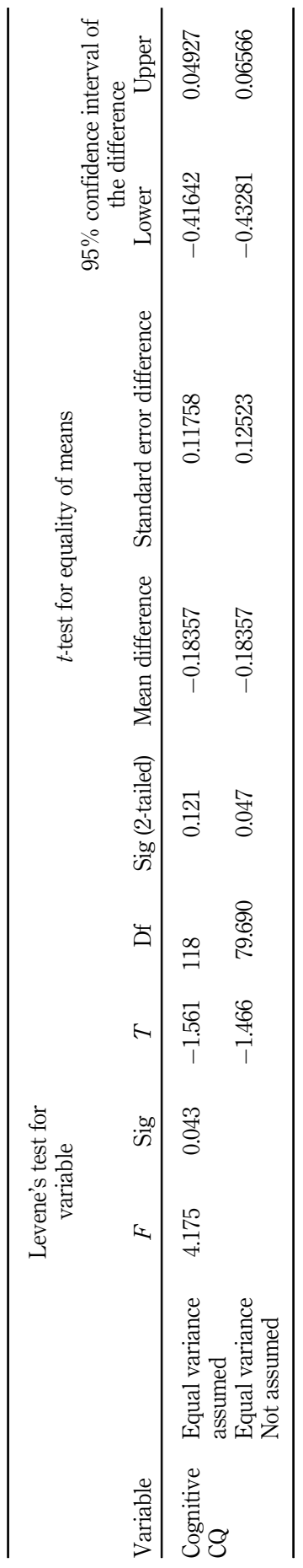



and cultural intelligence

221

Table 5.

Motivational cultural intelligence and foreign visits 
RAMJ

16,3

222

Table 6.

Behavioral cultural

intelligence and foreign visits

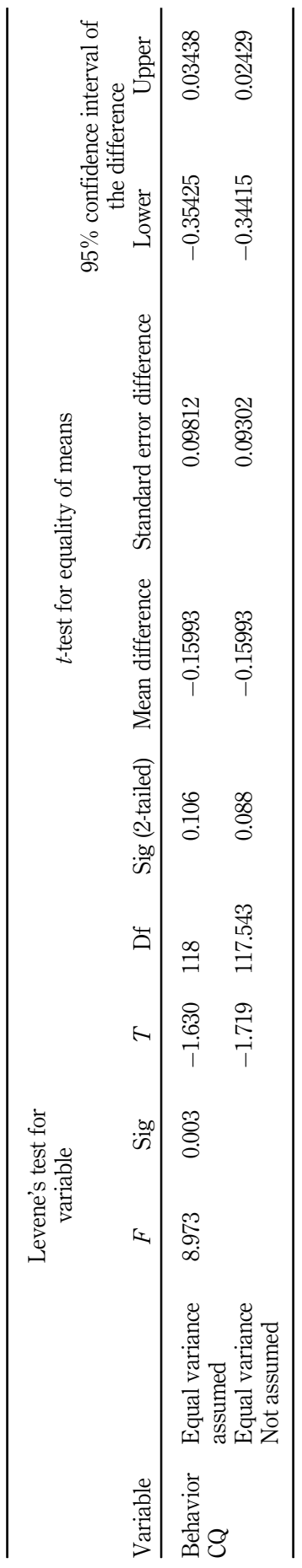


trips; however, future studies can be taken up to compare role of long-term foreign trips as well. The present study has compared two groups of employees by making foreign trips as a base for dividing them into groups. Future studies can be conducted to compare employees on demographic variables and well as professional background. A separate study can be conducted to compare role of short-term, long-run professional trips and recreational family trips.
Short-term foreign trips and cultural intelligence

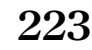

Result

Hypothesis Accepted Hypothesis Accepted Hypothesis Accepted Hypothesis Rejected
Table 7 .

Summary of result for proposed hypothesis

\section{References}

Ali, I., Ali, M., Leal-Rodríguez, A.L. and Albort-Morant, G. (2019), "The role of knowledge spillovers and cultural intelligence in enhancing expatriate employees' individual and team creativity", Journal of Business Research, Vol. 101, pp. 561-573.

Ang, S., Van Dyne, L. and Koh, C. (2006), "Personality correlates of the four-factor model of cultural intelligence", Group and Organization Management, Vol. 31 No. 1, pp. 100-23.

Ang, S., Van Dyne, L., Koh, C., Ng, K.Y., Templer, K.J., Tay, C. and Chandrasekar, N.A. (2007), "Cultural intelligence: its measurement and effects on cultural judgment and decision making, cultural adaptation and task performance", Management and Organization Review, Vol. 3, pp. 335-371.

Ang, S., Ng, K.Y. and Rockstuhl, T. (2020), "Cultural intelligence", in Sternberg, R.J. (Ed.), The Cambridge Handbook of Intelligence, Cambridge University Press, New York, NY, pp. 820-845.

Blasco, M., Feldt, L.E. and Jakobsen, M. (2012), "If only cultural chameleons could fly too: a critical discussion of the concept of cultural intelligence", International Journal of Cross Cultural Management, Vol. 12 No. 2, pp. 229-245.

Carter, C., Hunt, B.H., Mukonka, P.S., Viveash, S., Notter, J. and Toner, L. (2019), "I'll never be the same': the impact of an international elective", British Journal of Nursing, Vol. 28 No. 3, pp. 186-192.

Crowne, K.A. (2008), “What leads to cultural intelligence?", Business Horizons, Vol. 51, pp. 391-399.

Davies, J. and Easterby-Smith, M. (1984), "Learning and development from managerial work experiences”, Journal of Management Studies, Vol. 21 No. 2, pp. 169-182.

Dowling, P. (2008), International Human Resource Management: Managing People in a Multinational Context, South-Western Cengage Learning, Florence, KY.

Earley, P.C. and Ang, S. (2003), Cultural Intelligence: An Analysis of Individual Interactions across Cultures, Stanford University Press, Palo Alto, CA.

Earley, P.C. and Mosakowski, E. (2004), “Cultural intelligence”, available at: https:/hbr.org/2004/10/ cultural-intelligence (accessed 25 May 2019).

Earley, P.C. and Peterson, R.S. (2004), "The elusive cultural chameleon: cultural intelligence as a new approach to intercultural training for the global manager", The Academy of Management Learning and Education, Vol. 3 No. 1, pp. 100-115.

Earley, P.C., Ang, S. and Tan, J.S. (2006), CQ: Developing Cultural Intelligence at Work, Stanford University Press, Palo Alto, CA. 
RAMJ 16,3

Ely, R.J. and Thomas, D.A. (2001), "Cultural diversity at work: the effects of diversity perspectives on work group processes and outcomes", Administrative Science Quarterly, Vol. 46 No. 2, pp. 229-273.

Engle, R.L. and Crowne, K.A. (2014), "The impact of international experience on cultural intelligence: an application of contact theory in a structured short-term programme", Human Resource Development International, Vol. 17 No. 1, pp. 30-46.

Fang, T. (2005), "From 'onion' to 'ocean': paradox and change in national cultures", International Studies of Management and Organization, Vol. 35 No. 4, pp. 71-90.

Gabel, R.S., Dolan, S.L. and Cerdin, J.L. (2005), "Emotional intelligence as predictor of cultural adjustment for success in global assignments", Career Development International, Vol. 10 No. 5 , pp. 375-395.

Hofstede, G. (1980), Culture's Consequences: International Differences in Work-Related Values, Sage Publications, Beverly Hills, London.

Johnson, J.P., Lenartowicz, T. and Apud, S. (2006), "Cross-cultural competence in international business: toward a definition and a model", Journal of International Business Studies, Vol. 37 No. 4, pp. 525-543.

King, P.M. and Baxter Magolda, M.B. (2005), “A developmental model of intercultural maturity”, Journal of College Student Development, Vol. 46 No. 6, pp. 571-592.

Lee, L.Y. and Sukoco, B.M. (2010), "The effects of cultural intelligence on expatriate performance: the moderating effects of international experience", The International Journal of Human Resource Management, Vol. 21 No. 7, pp. 963-981.

Lin, Y.C., Chen, A.S.Y. and Song, Y.C. (2012), "Does your intelligence help to survive in a foreign jungle? The effects of cultural intelligence and emotional intelligence on cross-cultural adjustment", International Journal of Intercultural Relations, Vol. 36 No. 4, pp. 541-552.

Lustig, M. and Koester, J. (2006), Intercultural Competence: Interpersonal Communication across Cultures, Pearson and AB, Boston, MA.

MacNab, B., Brislin, R. and Worthley, R. (2012), "Experiential cultural intelligence development: context and individual attributes", The International Journal of Human Resource Management, Vol. 23 No. 7, pp. 1320-1341.

Mayerhofer, H., Linley Hartmann, C.L.C., Michelitsch-Ried, G. and Kollinger, I. (2007), "Flexpatriate assignments: a neglected issue in global staffing", International Journal of Human Resource Management, Vol. 15 No. 8, pp. 1371-1389.

Milliken, F.J. and Martins, L.L. (1996), "Searching for common threads: understanding the multiple effects of diversity in organizational groups", Academy of Management Review, Vol. 21, pp. 402-433.

Moon, J.A. (1999), Reflection in Learning and Professional Development: Theory and Practice, Routledge, London.

Ng, K.Y. and Earley, P.C. (2006), "Culture+ intelligence: old constructs, new frontiers", Group and Organization Management, Vol. 31 No. 1, pp. 4-19.

Opengart, R. (2018), "Short-term study abroad and the development of intercultural maturity", Journal of International Education in Business, Vol. 11 No. 2, pp. 241-255.

Phillion, J. (2002), "Becoming a narrative inquirer in a multicultural landscape", Journal of Curriculum Studies, Vol. 34 No. 5, pp. 535-556.

Sam, D.L. and Berry, J.W. (2010), "Acculturation: when individuals and groups of different cultural backgrounds meet”, Perspectives on Psychological Science, Vol. 5 No. 4, pp. 472-481.

Spradley, J.P. and McCurdy, D.W. (2012), Conformity and Conflict: Readings in Cultural Anthropology, Jill Potash, New York.

Tay, C., Westman, M. and Chia, A. (2008), "Antecedents and consequences of cultural intelligence among short-term business travelers", in Handbook of Cultural Intelligence: Theory, Measurement, and Applications, Part II, M E Sharpe, Armonk, New York, pp. 126-144. 
Ting-Toomey, S. and Kurogi, A. (1998), "Facework competence in intercultural conflict: an updated face-negotiation theory", International Journal of Intercultural Relations, Vol. 22 No. 2, pp. 187-225.

Van Dyne, L., Ang, S., Ng, K.Y., Rockstuhl, T., Tan, M.L. and Koh, C. (2012), "Subdimensions of the four factor model of cultural intelligence: expanding the conceptualization and measurement of cultural intelligence", Social and Personality Psychology Compass, Vol. 6 No. 4, pp. 295-313.

Vlajčić, D., Caputo, A., Marzi, G. and Dabić, M. (2019), "Expatriates managers' cultural intelligence as promoter of knowledge transfer in multinational companies", Journal of Business Research, Vol. 94, pp. 367-377.

Wu, P.C. and Ang, S.H. (2011), "The impact of expatriate supporting practices and cultural intelligence on cross-cultural adjustment and performance of expatriates in Singapore", The International Journal of Human Resource Management, Vol. 22 No. 13, pp. 2683-2702.

Zhang, Y. (2013), "Expatriate development for cross-cultural adjustment: effects of cultural distance and cultural intelligence", Human Resource Development Review, Vol. 12 No. 2, pp. 177-199.

\section{Further reading}

Gregory, R., Prifling, M. and Beck, R. (2009), "The role of cultural intelligence for the emergence of negotiated culture in IT offshore outsourcing projects", Information Technology and People, Vol. 22 No. 3, pp. 223-241.

Jassawalla, A., Truglia, C. and Garvey, J. (2004), "Cross-cultural conflict and expatriate manager adjustment”, Management Decision, Vol. 42 No. 7, pp. 837-849.

Wood, E. and St Peters, H.Y.Z. (2014), "Short-term cross-cultural study tours: impact on cultural intelligence", International Journal of Human Resource Management, Vol. 25 No. 4, pp. 558-70.

\section{Corresponding author}

Bhawana Bhardwaj can be contacted at: bhawnabhardwaj113@gmail.com

For instructions on how to order reprints of this article, please visit our website:

www.emeraldgrouppublishing.com/licensing/reprints.htm

Or contact us for further details: permissions@emeraldinsight.com 